\title{
Erratum to: Colonisation, racism and indigenous health
}

\section{Yin Paradies ${ }^{1}$}

\section{Erratum to: J Pop Research \\ DOI 10.1007/s12546-016-9159-y}

Unfortunately in the original publication of the article, Fig. 3 was processed incorrectly. The corrected Fig. 3 is given in this erratum.

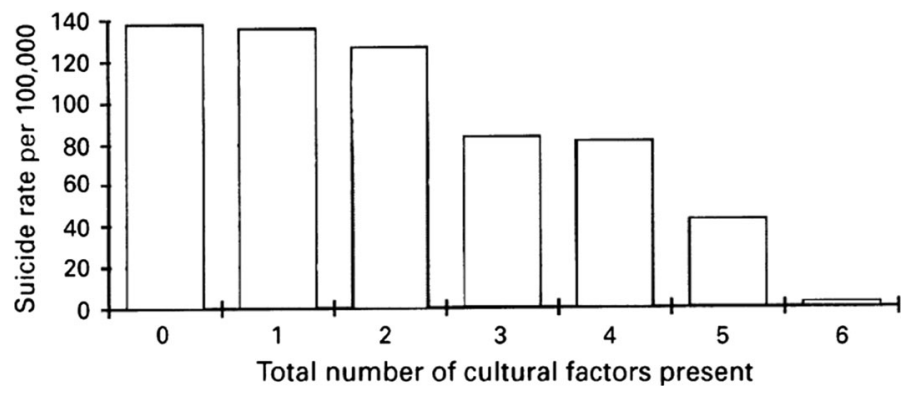

Fig. 3 Youth suicide rates by cultural factors in the community (Chandler and Lalonde 1998)

The online version of the original article can be found under doi:10.1007/s12546-016-9159-y.

Yin Paradies

yin.paradies@deakin.edu.au

1 Alfred Deakin Institute for Citizenship and Globalisation, Deakin University, 221 Burwood Highway, Burwood, Melbourne, VIC 3125, Australia 